Gut, 1984, 25, 121-124

\title{
Selective and non-selective beta receptor blockade in the reduction of portal pressure in patients with cirrhosis and portal hypertension
}

\author{
D WESTABY, D J BIHARI, A E S GIMSON, \\ I R CROSSLEY, AND ROGER WILLIAMS \\ From the Liver Unit, King's College Hospital and Medical School, London
}

SUMMARY To elucidate the mechanisms by which $\beta$ receptor blockade leads to a reduction of portal pressure, 18 patients with cirrhosis and portal hypertension were given comparable doses of propranolol or metoprolol. The fall in portal pressure was more marked with propranolol together with a significant reduction in hepatic blood flow, which was not seen with metoprolol. No correlation between the reduction in cardiac output and the decrease in portal pressure or changes in hepatic blood flow could be elicited in each group, but there was a direct relationship between the decrease in hepatic blood flow and fall in portal pressure in the propranolol treated patients. The difference observed may be related to blockade of $\beta_{2}$ vasodilator receptors in the splanchnic circulation which will occur only with propranolol and lead to a greater fall in splanchnic blood flow than will be produced by a reduction in cardiac output alone. Metoprolol, by maintaining effective hepatic blood flow, may be preferable to propranolol in patients with severely impaired liver function.

There is currently much interest in the use of $\beta$ receptor blockade in the prevention of bleeding from oesophageal varices after the initial results of a controlled trial by Lebrec $e t$ al in which propranolol was shown to reduce the chance of bleeding over a 12 month follow up period. ${ }^{1}$ Propranolol, in doses sufficient to reduce resting pulse rate by $25 \%$, produced a significant fall in hepatic blood flow and portal pressure, changes attributed by the authors to a fall in cardiac output. ${ }^{2}$ Some 14 years ago, however, Price et al showed that in normal subjects, after an intravenous bolus dose of propranolol, splanchnic blood flow fell by $29 \%$ whereas there was only a $6 \%$ reduction in cardiac output. ${ }^{3}$ The greater proportionate reduction in splanchnic blood flow, they suggested, was the result of blockade of $\beta$ vasodilator receptors on the splanchnic vessels (which are now thought to be $\beta_{2}$ in type ${ }^{4}$ ).

In the present study, we have investigated the effects of both a $\beta_{1}$ selective blocker, metoprolol, and the non-selective $\beta_{1}$ and $\beta_{2}$ blocker, propranolol, on cardiac output, hepatic blood flow,

Address for corrrespondence: Dr Roger Williams, FRCP, Liver Unit, King's College Hospital and Medical School, London SE5 8RX.

Received for publication 8 April 1983 and portal pressure in patients with cirrhosis and portal hypertension. Both drugs should have a similar capacity to reduce cardiac output by $\beta_{1}$ receptor blockade, whereas propranolol might be expected to have an added effect on hepatic blood flow and portal pressure from an action on $\beta_{2}$ receptors in the splanchnic circulation.

\section{Methods}

PATIENTS

The patients studied comprised 18 cases with biopsy proven cirrhosis and recent variceal haemorrhage, who had been haemodynamically stable for a minimum period of 48 hours, and in whom long term $\beta$ receptor blocking agents were being considered as therapy to prevent further variceal bleeding. All patients were grade A or B on a modified Child's classification ${ }^{5}$ and were included only if there was no previous history of airway obstruction, left ventricular failure, or diabetes.

Allocation to propranolol or metoprolol treatment groups was by a system of random numbers and the dose of each drug - given in multiples of an intravenous bolus of $2 \mathrm{mg}$ - was titrated over a period of five minutes to reduce 
cardiac output and/or pulse rate by approximately $15 \%$. Baseline measurements were taken of cardiac output by the thermodilution technique $;^{6}$ estimated hepatic blood flow by continuous infusion of indocyanine green and measurement of hepatic extraction by hepatic venous sampling - all patients had greater than $25 \%$ extraction of indocyanine green; ${ }^{7}$ and portal pressure by recording the gradient between the wedged and free hepatic venous pressure. ${ }^{8}$ Measurements were repeated 15 and 30 minutes after the administration of the allocated drug.

All results were expressed as the mean \pm SEM. Comparison between each group was made by the Student's $t$ test and within each group by the paired Student's $t$ test. The correlation between changes in estimated hepatic blood flow and portal pressure was made by regression analysis. The study was approved by the Ethical Committee of King's College Hospital, and informed consent was obtained from all patients.

\section{Results}

The two groups of patients were comparable in age, sex, aetiology, and severity of liver disease (Table 1) and the doses of propranolol and metoprolol administered were also comparable, with a mean of $11.25 \mathrm{mg}$ (range $4-20 \mathrm{mg}$ ) and $13.8 \mathrm{mg}$ (range 2-20 $\mathrm{mg}$ ) respectively. Both propranolol and metoprolol produced a significant fall in heart rate and cardiac output; the extent of these reductions being similar for the two drugs (Table 2). The fall in portal pressure with both drugs was significant compared with basal levels $(p<0.005)$, but was more marked with propranolol than metoprolol (mean 6.8 and 3.8 $\mathrm{mmHg}$ respectively) (Fig. 1) although this did not reach statistical significance $(0 \cdot 20>p>0 \cdot 10)$. The maximum fall in portal pressure was observed within 15 minutes of drug administration, and by 30

Table 1 Comparison of patient data in the propranolol and metoprolol groups

\begin{tabular}{lll}
\hline & $\begin{array}{l}\text { Propranolol } \\
\text { (9 patients) }\end{array}$ & $\begin{array}{l}\text { Metoprolol } \\
\text { (9 patients) }\end{array}$ \\
\hline Mean age (y) & $53 \cdot 8$ & $57 \cdot 0$ \\
Sex ratio (M:F) & $5: 4$ & $5: 4$ \\
Diagnosis & & \\
$\quad$ Alcoholic cirrhosis & 5 & 5 \\
$\quad$ Primary biliary cirrhosis & 2 & 2 \\
$\quad$ Cryptogenic cirrhosis & 1 & 1 \\
$\quad$ Chronic active hepatitis & 1 & 1 \\
Child's grading & 2 & 2 \\
A & 7 & 7 \\
B & & \\
\hline
\end{tabular}

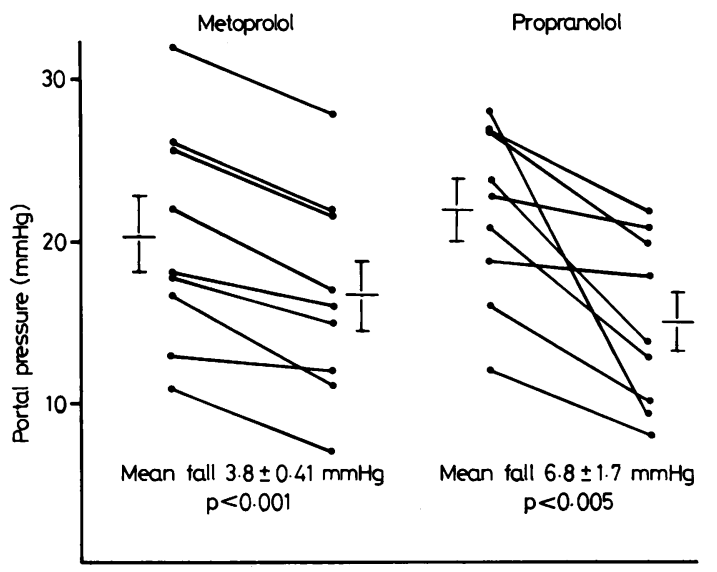

Fig. 1 Portal pressure (WHVP-FHVP) before and 15 minute after intravenous administration of propranolol or metoprolol.

minutes the pressure had risen again, although not back to basal levels.

Estimated hepatic blood flow was reduced by a mean of $20.4 \%$ in the propranolol group (pre $1.4 \pm 0.2 \mathrm{l} / \mathrm{min}$; at 15 minutes $1.1 \pm 0.2 \mathrm{l} / \mathrm{min}$, $\mathrm{p}<0.005)$, while there was no change with metoprolol (pre $1 \cdot 2 \pm 0.2 \mathrm{l} / \mathrm{min}$; at 15 minutes $1.2 \pm 0.23 \mathrm{l} / \mathrm{min}$ ) (Table 2). The fall in estimated hepatic blood flow with propranolol was significantly greater than the change with metoprolol (mean change estimated hepatic blood flow, $-306 \pm 70$ $\mathrm{ml} / \mathrm{min}$ and $+13 \pm 51 \mathrm{ml} / \mathrm{min}$ respectively, $\mathrm{p}<0.005$ ). There was a close correlation $(r=0 \cdot 80, y=1.51+0.62$ $x, p<0.01$ ) (Fig. 2) between the fall in estimated hepatic blood flow and the reduction in portal pressure in those receiving propranolol, but none following metoprolol $(\mathrm{r}=0.23, \mathrm{y}=24.50+0.50 \mathrm{x})$ (Fig. 3). No direct correlation was observed between the fall in cardiac output, which was similar in both drugs, and the reductions in portal pressure observed.

\section{Discussion}

Although both metoprolol and propranolol were shown to significantly reduce portal pressure, there was a trend towards a greater fall with propranolol despite a similar fall in cardiac output. This would suggest a reduction in cardiac output is not the only mechanism involved in the effect of propranolol on portal pressure. The existence of vasodilator $\beta_{2}$ receptors on the splanchnic vessels has already been referred to ${ }^{34}$ and blockade of these receptors by propranolol (leaving unopposed $\alpha$ vasocon- 
Table 2 Changes in portal pressure (WHVP-FHVP), hepatic blood flow, cardiac output, and pulse rate before and 15 minutes after intravenous propranolol or metoprolol

\begin{tabular}{|c|c|c|c|c|c|c|}
\hline & \multicolumn{3}{|c|}{ Propranolol $(n=9)$} & \multicolumn{3}{|c|}{ Metoprolol $(n=9)$} \\
\hline & Before & $\begin{array}{l}15 \mathrm{~min} \\
\text { after }\end{array}$ & $p$ & Before & $\begin{array}{l}15 \mathrm{~min} \\
\text { after }\end{array}$ & $p$ \\
\hline Portal pressure (WHVP-FHVP) $\mathrm{mmHg}$ & $21 \cdot 9 \pm 1 \cdot 8$ & $15 \cdot 1 \pm 1 \cdot 8$ & $<0.005$ & $20 \cdot 5 \pm 2 \cdot 3$ & $16 \cdot 7 \pm 2 \cdot 2$ & $<0.001$ \\
\hline Hepatic blood flow (1/min) & $1 \cdot 4 \pm 0 \cdot 2$ & $1 \cdot 1 \pm 0 \cdot 2$ & $<0.005$ & $1 \cdot 2 \pm 0 \cdot 2$ & $1 \cdot 2 \pm 0 \cdot 2$ & NS \\
\hline Cardiac output ( $1 / \mathrm{min})$ & $8 \cdot 2 \pm 0 \cdot 5$ & $7 \cdot 1 \pm 0 \cdot 1$ & $<0.01$ & $8 \cdot 2 \pm 0 \cdot 6$ & $6 \cdot 8 \pm 0 \cdot 5$ & $<0.005$ \\
\hline Heart rate/min & $85 \cdot 0 \pm 3 \cdot 8$ & $68 \cdot 1 \pm 3 \cdot 4$ & $<0.001$ & $93 \cdot 0 \pm 2 \cdot 5$ & $74 \cdot 4 \pm 1 \cdot 7$ & $<0.001$ \\
\hline
\end{tabular}

striction), in combination with the fall in cardiac output consequent upon $\beta_{1}$ receptor blockade, may account for the significant fall in hepatic blood flow and the greater fall in portal pressure with propranolol as compared with metoprolol.

The reductions in portal pressure observed with metoprolol can only be due to a fall in cardiac output, for $\beta_{1}$ receptors are thought to be restricted in their distribution to the myocardium. There was no direct correlation, however, between the reductions in cardiac output and portal pressure, and the fall in portal pressure with no change in effective hepatic blood flow is difficult to explain. Portal blood flow and pressure could be influenced by a decrease in cardiac output in two ways. Firstly, if the proportion of the cardiac output reaching the splanchnic circulation is constant before and after administration of a $\beta_{1}$ blocker, the reduction in cardiac output will lead to a fall in splanchnic blood flow and, as a consequence, portal blood flow and pressure will fall. Secondly, a fall in systemic arterial pressure concomitant with the fall in cardiac output will initiate a baroreceptor mediated sympathetic response resulting in splanchnic vasoconstriction.

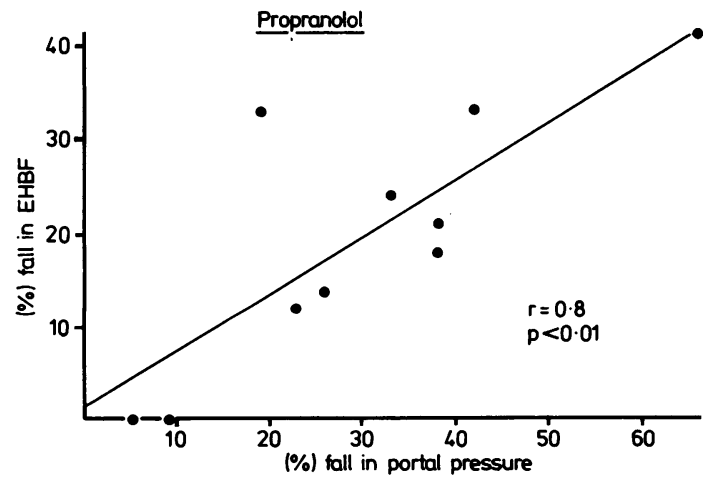

Fig. 2 Relationship between fall in estimated hepatic blood flow (EHBF) and reduction in portal pressure after intravenous administration of propranolol.
Nevertheless, although metoprolol produced significant reductions in portal pressure, no fall in hepatic blood flow was observed. A possible explanation for this would be a reduction in intrahepatic portal resistance secondary to a fall in hepatic arterial perfusion pressure - a reflex known to occur in the control of hepatic blood flow in the dog. ${ }^{8}$ Such a reduction in hepatic portal resistance in a cirrhotic patient with portosystemic collateral blood flow may result in an increase in blood flow into the liver, in association with a decrease in extrahepatic shunted blood. Effective hepatic blood flow assessed by indocyanine green extraction would, therefore, remain unchanged despite an overall reduction of splanchnic blood flow, and the pressure within the portal system would fall.

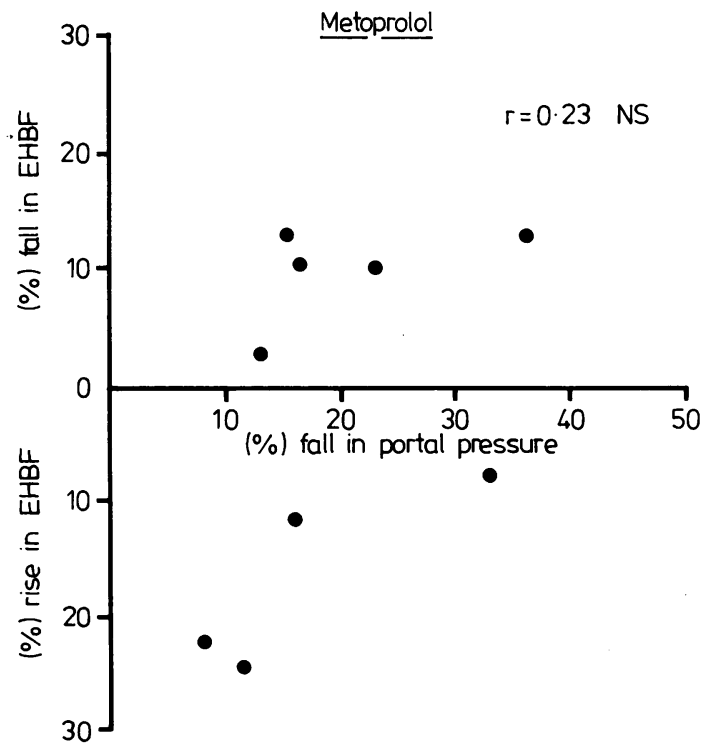

Fig. 3 Relationship between change in estimated hepatic blood flow (EHBF) and reduction in portal pressure after intravenous administration of metoprolol. 
Similar changes in hepatic haemodynamics would be expected to follow propranolol administration. The combination of $\beta_{1}$ and $\beta_{2}$ receptor blockade, however, may reduce splanchnic blood flow to such a degree that falls in hepatic portal resistance are unable to compensate for the greater decline in blood flow.

There are certain clinical implications to be drawn from the results of this study. Although the fall in portal pressure with propranolol tends to be greater than with metoprolol, the associated marked reduction in hepatic blood flow may have long term deleterious effects on liver function. Although this was not observed in a clinical trial of propranolol in the prevention of variceal bleeding in patients with cirrhosis, ${ }^{1}$ to date the drug has only been used in patients with very well compensated liver disease. It may be that the smaller fall in portal pressure obtained with metoprolol could be equally effective in preventing recurrence of variceal bleeding, and the maintenance of overall hepatic blood flow preferable, especially in patients with Child's grade $\mathrm{C}$ category disease.

We are indebted to Ciba-Geigy Research Laboratories for their support.

\section{References}

1 Lebrec D, Poynard T, Hillon P, Benhamou JP. Propranolol for prevention of recurrent gastrointestinal bleeding in patients with cirrhosis. A controlled study. $N$ Engl J Med 1981; 305: 1371-4.

2 Lebrec D, Nouel O, Corbic M, Benhamou JP. Propranolol - a medical treatment for portal hypertension? Lancet 1980; 2: 180-2.

3 Price HL, Cooperman HL, Warden JC. Control of the splanchnic circulation in man. Role of beta-adrenergic receptors. Circulation Res 1967; 21: 333-40.

4 Richardson PDI, Withrington PG. Liver blood flow. Gastroenterology 1981; 81: 356-75.

5 Pugh RNH, Murray-Lyon IM, Dawson JL, Pietroni MC, Williams R. Transection of the oesophagus for bleeding oesophageal varices. $\mathrm{Br} J$ Surg 1973; 60: 646-9.

6 Forrester JS, Ganz W, Diamond G et al. Thermodilution cardiac output determination with a single flow-directed catheter. Am Heart J 1972; 83: 306-11.

7 Caesar J, Shaldon S, Chiandussi L, Guevara L, Sherlock S. The use of indocyanine green in the measurement of hepatic blood flow and as a test of hepatic function. Clin Sci 1961; 21: 43-57.

8 Myers JD, Taylor WJ. An estimation of portal venous pressure by occlusive catheterisation of an hepatic venule. J Clin Invest 1951; 30: 662. 